\title{
Matrix-associated autologous chondrocyte implantation with autologous bone grafting of osteochondral lesions of the talus in adolescents: patient-reported outcomes with a median follow-up of 6 years
}

Daniel Körner ${ }^{1 *}\left(\mathbb{D}\right.$, Christoph E. Gonser ${ }^{1}$, Stefan Döbele ${ }^{1}$, Christian Konrads ${ }^{1}$, Fabian Springer ${ }^{2,3}$ and Gabriel Keller ${ }^{2}$

\begin{abstract}
Background: This study presents patient-reported outcome measures after combined matrix-associated autologous chondrocyte implantation and autologous bone grafting in high-stage osteochondral lesions of the talus in adolescents.

Methods: A total of 12 adolescent patients (13 ankles) received matrix-associated autologous chondrocyte implantation and autologous bone grafting for a solitary osteochondral lesion of the talus at a single centre. The Foot and Ankle Outcome Score and Foot and Ankle Ability Measure were defined as outcome measures (median follow-up 80 months [range 22-107 months]). Pre- and postoperative ankle radiographs were evaluated according to the van Dijk ankle osteoarthritis scale.

Results: The study population consisted of four male and nine female cases (mean age at the time of surgery, $17.7 \pm 2.1$ years). Eight lesions were classified as traumatic and five as idiopathic. Twelve lesions were located medial vs one lateral in the coronal plane and all central in the sagittal plane. The median lesion size and depth were $1.3 \mathrm{~cm}^{2}$ (range $0.9-3.2 \mathrm{~cm}^{2}$ ) and $5 \mathrm{~mm}$ (range 5-9 $\mathrm{mm}$ ), respectively.

There were no perioperative complications in any of the cases.

In 9 cases patient-reported outcome measures were available. The results of the Foot and Ankle Outcome Score subscales were symptoms, $70 \pm 14$; pain, $83 \pm 10$; activities of daily living, $89 \pm 12$; sports/recreational activities, $66 \pm$ 26; and quality of life, $51 \pm 17$. The mean overall Foot and Ankle Outcome Score was $78 \pm 13$.

The results of the Foot and Ankle Ability Measure subscales were activities of daily living, $81 \pm 20$; function/activities of daily living, $84 \pm 13$; sports, $65 \pm 29$; and function/sports, $73 \pm 27$. According to the function overall subscale of the Foot (Continued on next page)
\end{abstract}

\footnotetext{
* Correspondence: dkoerner@bgu-tuebingen.de

'Department of Traumatology and Reconstructive Surgery, BG Trauma

Center Tübingen, Eberhard Karls University Tübingen, Schnarrenbergstr. 95, 72076 Tübingen, Germany

Full list of author information is available at the end of the article
}

(c) The Author(s). 2021 Open Access This article is licensed under a Creative Commons Attribution 4.0 International License, which permits use, sharing, adaptation, distribution and reproduction in any medium or format, as long as you give appropriate credit to the original author(s) and the source, provide a link to the Creative Commons licence, and indicate if changes were made. The images or other third party material in this article are included in the article's Creative Commons licence, unless indicated otherwise in a credit line to the material. If material is not included in the article's Creative Commons licence and your intended use is not permitted by statutory regulation or exceeds the permitted use, you will need to obtain permission directly from the copyright holder. To view a copy of this licence, visit http://creativecommons.org/licenses/by/4.0/. The Creative Commons Public Domain Dedication waiver (http://creativecommons.org/publicdomain/zero/1.0/) applies to the data made available in this article, unless otherwise stated in a credit line to the data. 


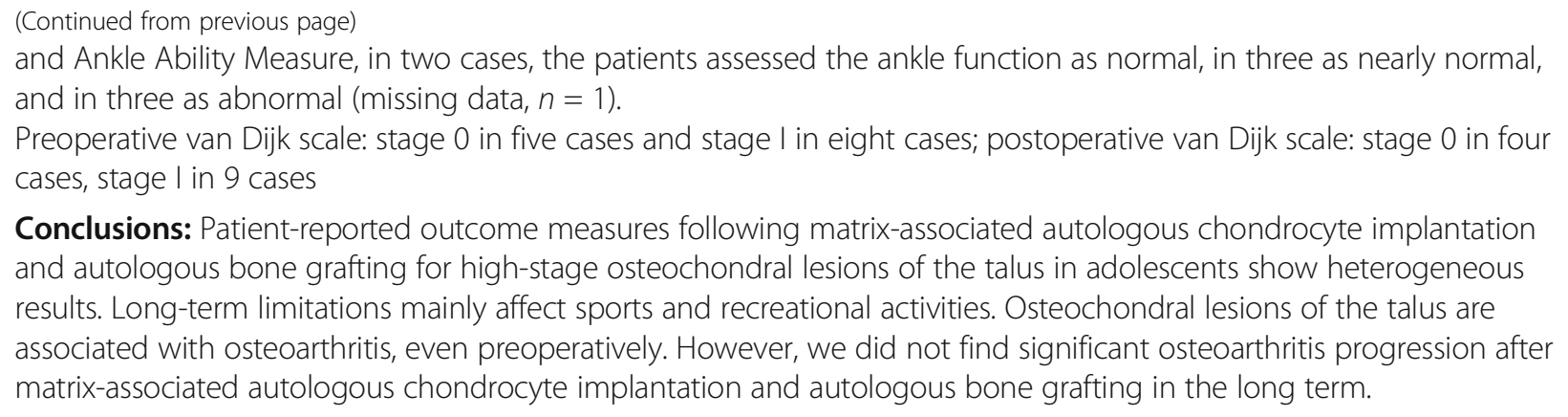

Conclusions: Patient-reported outcome measures following matrix-associated autologous chondrocyte implantation and autologous bone grafting for high-stage osteochondral lesions of the talus in adolescents show heterogeneous results. Long-term limitations mainly affect sports and recreational activities. Osteochondral lesions of the talus are associated with osteoarthritis, even preoperatively. However, we did not find significant osteoarthritis progression after matrix-associated autologous chondrocyte implantation and autologous bone grafting in the long term.

Keywords: Osteochondral lesion, Ankle, Talus, Children, Adolescents, Autologous bone grafting, Autologous chondrocyte implantation, Matrix-associated autologous chondrocyte implantation, Patient-reported outcome measures, Osteoarthritis

\section{Background}

Osteochondral lesions of the talus (OCLTs) are rare in pre-school children but become more frequent in schoolchildren and especially female adolescents [1]. Except for acute flake fractures, the primary treatment is conservative [2]. Operative therapy options of OCLTs in the paediatric and adolescent population vary; there is a lack of internationally accepted treatment guidelines. For low-stage OCLTs, good clinical results have been reported after arthroscopic treatment with bone marrow stimulation (BMS) techniques, fragment fixation, and retrograde drilling [3-8]. However, relatively high reoperation rates due to treatment failure have also been reported [9]. There is little evidence regarding the operative treatment of high-stage OCLTs in children and adolescents.

Different expert groups have proposed thresholds for cartilage replacement therapies such as matrix-associated autologous chondrocyte implantation (MACI) and matrixinduced bone marrow stimulation (M-BMS) at a defect size of $1.0 \mathrm{~cm}^{2}$ [10] and $1.5 \mathrm{~cm}^{2}$ [11, 12], respectively. In the case of deep subchondral bone loss, additional autologous bone grafting (ABG) can be performed. The threshold for bone grafting in addition to scaffold-based therapies (MACI or M-BMS) has been defined at a defect depth of $3 \mathrm{~mm}$ [10] and $5 \mathrm{~mm}$ [12], respectively.

In a large case series, Kramer et al. analysed the results of surgical treatment of 109 osteochondral lesions of the ankle (107 OCLTs and two osteochondral lesions of the distal tibia) of 100 patients with a mean age of $14.3 \pm 2.3$ years over a median follow-up period of 3.3 years [9]. The patient population showed Berndt/Harty stages I to IV lesions. Different surgical techniques such as transarticular drilling (54\%), fragment fixation (20\%), and excision microfracture $(26 \%)$ were used. The authors found that female sex and higher BMI were associated with worse Foot and Ankle Outcome Score (FAOS) outcomes. However, no significant difference in FAOS scores was detected according to the procedures used or the postoperative radiographic findings [9].

To the best of our knowledge, no study has yet reported long-term clinical outcome data after MACI/ ABG in a paediatric and adolescent patient population with high-stage OCLTs. The aim of this study is to present patient-reported outcome measures (PROMs) after combined MACI/ABG in adolescents.

\section{Methods}

\section{Study population}

Between 2012 and 2018, 12 adolescent patients (13 ankles) received MACI/ABG for a solitary OCLT at our trauma centre. The patient files and imaging data that were digitally available in the picture archiving and communication system were retrospectively analysed. Further, the patients were followed up using PROMs. The following inclusion criteria were defined: presence of a solitary OCLT, operative treatment with $\mathrm{MACI} / \mathrm{ABG}$ at our institution, and patient age 20 years or younger at the time of MACI/ABG. The World Health Organization defines adolescence as the period of life between the ages of 10 and 20 .

\section{Data capture}

Epidemiological data such as age at the time of MACI/ $\mathrm{ABG}$, gender, and body mass index (BMI) were captured. Furthermore, data about the OCLT were analysed, such as the side of injury and the location at the talus (coronal: medial vs central vs lateral; sagittal: anterior vs central vs posterior). It was recorded whether the tibial plafond showed a corresponding lesion.

The aetiology of the OCLT was classified as traumatic when there was a history of trauma in the medical history of the patient. Otherwise, the OCLT was classified as idiopathic.

The OCLTs were classified according to the International Cartilage Repair Society (ICRS) classification and the Berndt-Harty-Loomer (BHL) classification [13]. 
The lesion size and depth were evaluated based on preoperative cross-sectional imaging (preoperative magnetic resonance imaging was available for retrospective analysis in eight cases, computed tomography in eleven cases). The lesion size was calculated by multiplying length and width.

It was registered whether and when there had been previous operations to that ankle/OCLT. Complications following MACI/ABG were also captured.

\section{Operative technique}

The decision for MACI/ABG was based on medical history, clinical examination findings, preoperative imaging, patient preferences, and findings in ankle arthroscopy. MACI/ABG was considered in the case of ICRS stage 4 cartilage damage with a lesion size $\geq 1.0 \mathrm{~cm}^{2}$ and/or lesion depth $\geq 5 \mathrm{~mm}$.

MACI/ABG was performed as a two-stage procedure. In the first step, ankle arthroscopy was performed to evaluate the articular cartilage. If the indication for MACI/ABG was confirmed, cartilage was harvested from an area outside the main weightbearing zone of the talus and sent to the manufacturer. In one case, arthroscopy with retrograde drilling of the OCLT was combined with chondrocyte harvesting.

After cultivation, the MACI scaffold was implanted in a second procedure. Novocart ${ }^{\circ}$ 3D (Tetec AG, Reutlingen, Germany) was used in nine cases, and Novocart ${ }^{\circ}$ Inject (Tetec AG, Reutlingen, Germany) was used in four cases. After medial $(n=12)$ or lateral $(n=1)$ malleolar osteotomy, the OCLT was debrided, and sharp cartilage rims were cut. For ABG, bone cylinders were harvested from the ipsilateral $(n=11)$ or contralateral $(n$ $=2$ ) iliac crest and placed into the bony talar defect. The MACI scaffold was placed onto the bone. In the case of Novocart $^{\circ} 3 \mathrm{D}$, the matrix was fixed to the surrounding cartilage with absorbable sutures. The osteotomy of the malleolus was fixed with tension band wiring $(n=5)$, screw fixation $(n=7)$, or plating $(n=1$, lateral malleolus).

The rehabilitation protocol consisted of partial weight bearing $(20 \mathrm{~kg})$ in a lower leg orthosis for 6 weeks after the procedure.

In seven cases, hardware removal was performed in our institution combined with follow-up arthroscopy (mean time between MACI/ABG and hardware removal/follow-up arthroscopy $12 \pm 5$ months). One of those patients underwent a revision operation in the further course because of cyst formation at the medial malleolus (case no. 3). In the remaining cases, the hardware removal was performed without arthroscopy $(n=3)$ or in another hospital $(n=3)$.

\section{Outcome measures}

The German versions of the FAOS [14] and Foot and Ankle Ability Measure (FAAM) [15] were defined as outcome measures. The questionnaires were sent to the patients; they were asked whether they had undergone any re-operation after treatment at our institution. Eight of the 12 patients with nine MACI/ABG procedures returned the completed PROMs. The median follow-up was 80 months (range 22-107 months).

Furthermore, both preoperative and the last available postoperative ankle radiographs (anteroposterior and lateral views) were evaluated according to the van $\mathrm{Dijk}$ ankle osteoarthritis (OA) scale (median follow-up 8 months [range 1-67 months]) [16, 17].

\section{Statistical analysis}

Statistical analysis was performed using the software package JMP (SAS Institute Inc., JMP, Version 12.2.0, Cary, NC, USA). The Shapiro-Wilk $W$ test was applied to screen the data for normality of distribution. Mean and standard deviation for normally distributed data as well as median and range for non-normally distributed data were reported. Descriptive statistics were carried out.

\section{Compliance with ethical standards}

The study was performed according to the ethical standards of the institutional and national research committee and according to the 1964 Helsinki Declaration and its later amendments. The institutional review board approved this study (identification number: 180/2020BO1).

Patients who returned the PROMs gave their informed consent. For patients who were lost to follow-up $(n=4)$, consent was waived, since in these patients only a retrospective, pseudonymised data evaluation was performed.

The authors declare that they have no potential conflicts of interest.

\section{Results}

Table 1 shows the demographic and lesion characteristics of the study population. The study population consisted of four male and nine female cases in 12 patients (mean age at the time of MACI/ABG $17.7 \pm 2.1$ years). The median BMI was $23.5 \mathrm{~kg} / \mathrm{m}^{2}$ (range 18.0-39.3 kg/ $\mathrm{m}^{2}$ ). The distal tibial physis was closed in all patients. The median lesion size and depth were $1.3 \mathrm{~cm}^{2}$ (range $0.9-3.2 \mathrm{~cm}^{2}$ ) and $5 \mathrm{~mm}$ (range $5-9 \mathrm{~mm}$ ), respectively.

There were no perioperative complications in any of the cases after MACI/ABG $(n=13)$. In one case (case number 3), there were complications during hardware removal/follow-up arthroscopy 11 months after MACI/ ABG, with difficult screw removal from the medial malleolus. In the further course, an osseous cyst developed on the medial malleolus, which was finally treated with 
Table 1 Demographic and lesion characteristics

\begin{tabular}{|c|c|c|c|c|c|c|c|c|c|c|c|c|c|c|}
\hline \multirow[t]{2}{*}{ Patient } & \multirow[t]{2}{*}{ Case } & \multirow{2}{*}{$\begin{array}{l}\text { Age } \\
\text { (years) }\end{array}$} & \multirow[t]{2}{*}{ Sex } & \multirow{2}{*}{$\begin{array}{l}\text { BMI } \\
\left(\mathrm{kg} / \mathrm{m}^{2}\right)\end{array}$} & \multirow[t]{2}{*}{ Aetiology } & \multirow[t]{2}{*}{ Previous operations } & \multirow[t]{2}{*}{ Side } & \multicolumn{2}{|l|}{ Location } & \multirow{2}{*}{$\begin{array}{l}\text { Tibial } \\
\text { lesion }\end{array}$} & \multirow[t]{2}{*}{ ICRS } & \multirow[t]{2}{*}{$\mathrm{BHL}$} & \multirow{2}{*}{$\begin{array}{l}\text { Size } \\
\left(\mathrm{cm}^{2}\right)\end{array}$} & \multirow{2}{*}{$\begin{array}{l}\text { Depth } \\
(\mathrm{mm})\end{array}$} \\
\hline & & & & & & & & Coronal & $\overline{\text { Sagittal }}$ & & & & & \\
\hline 1 & 1 & 17 & $\mathrm{~F}$ & 24.6 & $\mathrm{~T}$ & $\begin{array}{l}\text { 2: Arthroscopy, retrograde } \\
\text { drilling }^{\text {a }} \text { re-arthroscopy, } \\
\text { retrograde drilling, BMS } \\
\text { distal tibia }\end{array}$ & $\mathrm{R}$ & Med. & C. & Yes & 4 & 3 & 1.4 & 5 \\
\hline 1 & 2 & 19 & $\mathrm{~F}$ & 25.4 & $\mathrm{~T}$ & 0 & L & Med. & C. & No & 4 & 3 & 1.0 & 5 \\
\hline 2 & 3 & 18 & $\mathrm{~F}$ & 23.3 & । & 0 & $\mathrm{R}$ & Med. & C. & No & 4 & 3 & 1.1 & 5 \\
\hline 3 & 4 & 14 & $\mathrm{~F}$ & 18.1 & । & 0 & $\mathrm{R}$ & Med. & C. & No & 4 & 3 & b & b \\
\hline 4 & 5 & 20 & $F$ & 18.0 & $\mathrm{~T}$ & 0 & $\mathrm{R}$ & Lat. & C. & No & 4 & 4 & 1.2 & 5 \\
\hline 5 & 6 & 20 & M & 23.5 & । & $\begin{array}{l}\text { 1: Arthroscopy, retrograde } \\
\text { drilling }\end{array}$ & $\mathrm{R}$ & Med. & C. & No & 4 & 4 & 1.1 & 9 \\
\hline 6 & 7 & 20 & $F$ & 18.8 & I & 0 & L & Med. & C. & No & 4 & 3 & 1.1 & 5 \\
\hline 7 & 8 & 15 & $\mathrm{~F}$ & 24.0 & $T$ & $\begin{array}{l}\text { 2: Arthroscopya; re-arthroscopy, } \\
\text { BMS }\end{array}$ & $\mathrm{R}$ & Med. & C. & No & 4 & 3 & 1.9 & 7 \\
\hline 8 & 9 & 20 & $M$ & 26.0 & $\mathrm{~T}$ & 0 & L & Med. & C. & No & 4 & 3 & 0.9 & 5 \\
\hline 9 & 10 & 15 & F & 30.5 & I & 0 & L & Med. & C. & No & 4 & 3 & 1.6 & 5 \\
\hline 10 & 11 & 18 & $M$ & 23.5 & $\mathrm{~T}$ & 0 & L & Med. & C. & No & 4 & 4 & 3.2 & 5 \\
\hline 11 & 12 & 16 & F & 22.3 & $\mathrm{~T}$ & $\begin{array}{l}\text { 1: Arthroscopy, retrograde } \\
\text { drilling }\end{array}$ & $\mathrm{R}$ & Med. & C. & No & 4 & 3 & 1.6 & 5 \\
\hline 12 & 13 & 18 & $M$ & 39.3 & $\mathrm{~T}$ & 0 & $\mathrm{R}$ & Med. & C. & Yes & 4 & 3 & 1.6 & 6 \\
\hline
\end{tabular}

$B H L$, Berndt-Harty-Loomer classification; $B M I$, body mass index; $B M S$, bone marrow stimulation; ICRS, International Cartilage Repair Society classification; $F$, female; $M$, male; I, idiopathic; $T$, traumatic; $L$, left; $R$, right; Lat., lateral; Med., medial; $C$. , central

a'Other hospital

${ }^{\mathbf{b}}$ Missing data

autologous bone grafting after 14 months. The remaining cases in the follow-up population had no reoperation within the follow-up period. The cases lost to follow-up $(n=4)$ had no re-operations for the period when they were treated in our institution (median 7 months, range 1-13 months).
The clinical outcomes according to the FAOS and FAAM scores for every case are presented in Table 2 . The mean overall FAOS score was $78 \pm 13$. Figure 1 shows the results of the five FAOS subscales, and Fig. 2 shows the results of the FAAM subscales activities of

Table 2 Patient-reported outcome scores (Foot and Ankle Outcome Score and Foot and Ankle Ability Measure)

\begin{tabular}{|c|c|c|c|c|c|c|c|c|c|c|c|c|c|}
\hline \multirow[t]{2}{*}{ Patient } & \multirow[t]{2}{*}{ Case } & \multirow[t]{2}{*}{ FU (months) } & \multicolumn{6}{|c|}{ Foot and Ankle Outcome Score } & \multicolumn{5}{|c|}{ Foot and Ankle Ability Measure } \\
\hline & & & Symptoms & Pain & $A D L$ & $\begin{array}{l}\text { Sports/ } \\
\text { recreation }\end{array}$ & $Q O L$ & Overall & $A D L$ & $\begin{array}{l}\text { Function/ } \\
A D L\end{array}$ & Sports & $\begin{array}{l}\text { Function/ } \\
\text { sports }\end{array}$ & $\begin{array}{l}\text { Function } \\
\text { overall }\end{array}$ \\
\hline 1 & 1 & 107 & 75 & 83 & 94 & 80 & 56 & 83 & 94 & 90 & 78 & 90 & Nearly normal \\
\hline 1 & 2 & 83 & 93 & 97 & 100 & 95 & 69 & 95 & 98 & 95 & 91 & 95 & Normal \\
\hline 2 & 3 & 96 & 75 & 78 & 85 & 60 & 44 & 75 & 61 & 80 & 47 & 70 & Missing \\
\hline 3 & 4 & L & & & & & & & & & & & \\
\hline 4 & 5 & 96 & 61 & 69 & 63 & 25 & 38 & 57 & 43 & 65 & 16 & 15 & Abnormal \\
\hline 5 & 6 & 80 & 50 & 69 & 76 & 40 & 19 & 61 & 70 & 75 & 31 & 45 & Abnormal \\
\hline 6 & 7 & L & & & & & & & & & & & \\
\hline 7 & 8 & 47 & 71 & 97 & 100 & 80 & 75 & 90 & 99 & 100 & 84 & 85 & Nearly normal \\
\hline 8 & 9 & L & & & & & & & & & & & \\
\hline 9 & 10 & L & & & & & & & & & & & \\
\hline 10 & 11 & 26 & 75 & 83 & 94 & 75 & 56 & 83 & 92 & 85 & 84 & 70 & Nearly normal \\
\hline 11 & 12 & 24 & 50 & 78 & 90 & 40 & 44 & 70 & 77 & 65 & 53 & 85 & Abnormal \\
\hline 12 & 13 & 22 & 79 & 89 & 99 & 95 & 56 & 89 & 98 & 99 & 97 & 99 & Normal \\
\hline
\end{tabular}

$F U$, follow-up; $A D L$, activities of daily living; $Q O L$, quality of life; $L$, lost to follow-up 


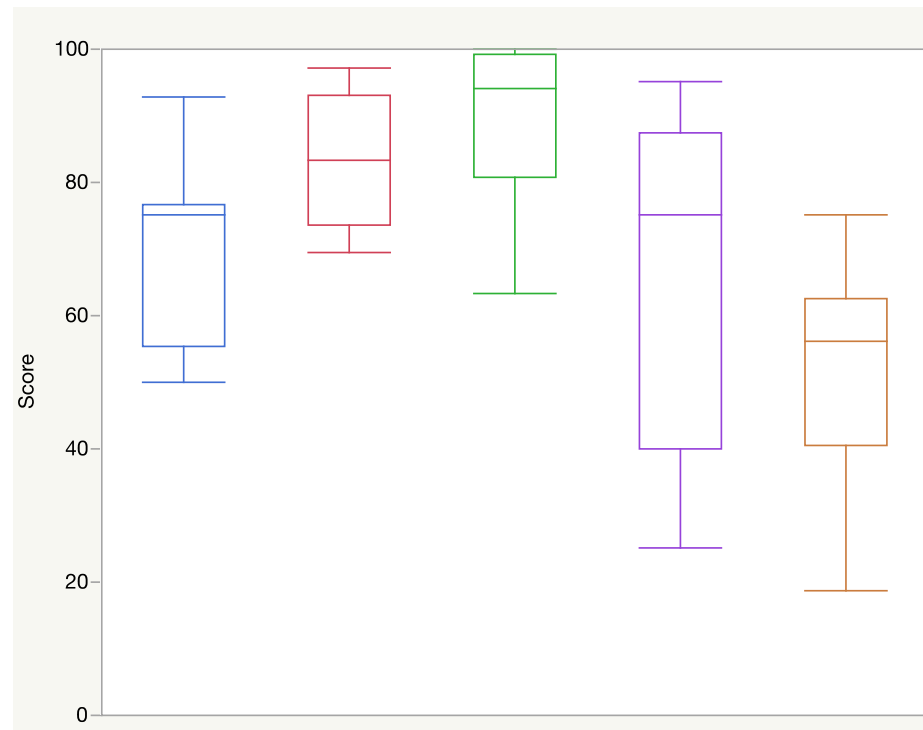

中 Symptoms

фे Pain

宁 ADL

中 Sports/Recreation

फ QOL

Fig. 1 Box plots of the five Foot and Ankle Outcome Score subscales (mean \pm standard deviation): symptoms, $70 \pm 14 ;$ pain, $83 \pm 10 ;$ activities of daily living (ADL), $89 \pm 12$; sports/recreational activities, $66 \pm 26$; quality of life (QOL), $51 \pm 17$

daily living, function/activities of daily living, sports, and function/sports.

Table 3 indicates the pre- and postoperative radiographic findings according to the van Dijk ankle OA scale. In eight cases (62\%), the preoperative radiographs showed stage 1 OA (vs five cases [38\%] without signs of $\mathrm{OA})$. In the postoperative radiographs, nine patients
(69\%) had stage $1 \mathrm{OA}$ and four patients (31\%) stage 0 OA.

Patients who assessed their function overall according to the FAAM score to be normal $(n=2)$ or nearly normal $(n=3)$ showed stage 1 OA in four cases $(80 \%)$ and no signs of $\mathrm{OA}$ in one case $(20 \%)$ on postoperative radiographs. In contrast, in patients who assessed their function overall to be abnormal $(n=3)$, postoperative
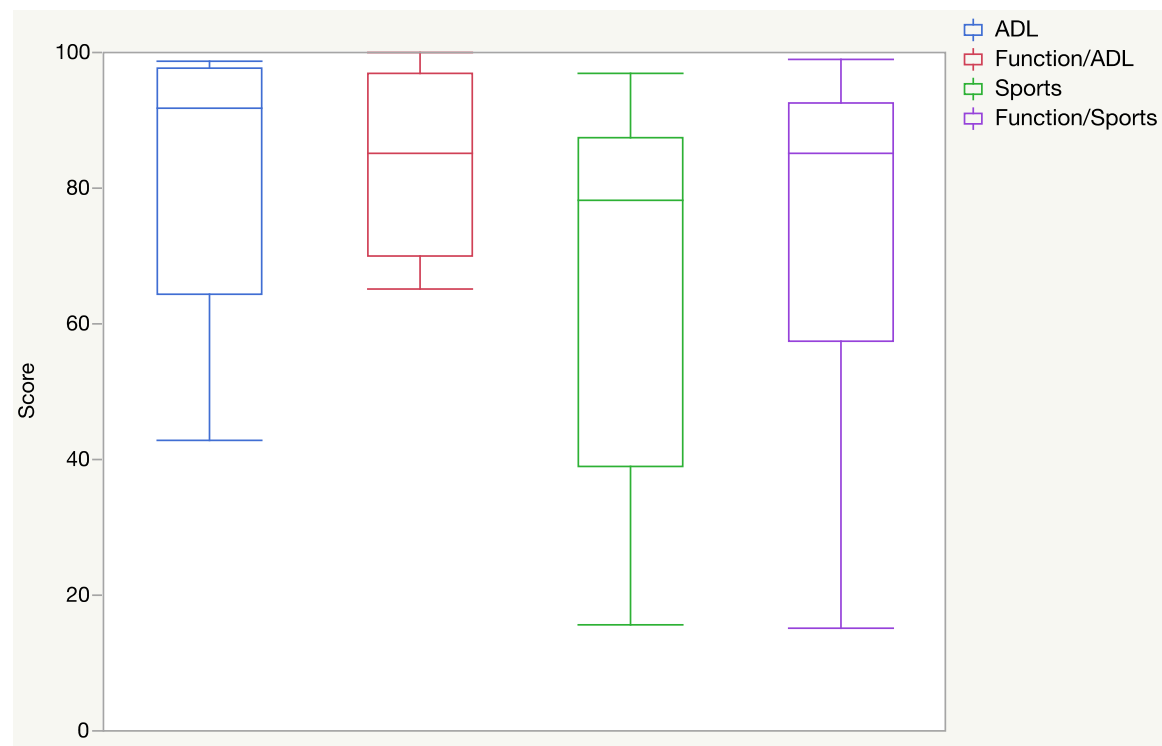

Fig. 2 Box plots of the four Foot and Ankle Ability Measure subscales (mean \pm standard deviation): activities of daily living (ADL), $81 \pm 20$; function/ADL, $84 \pm 13$; sports, $65 \pm 29$; function/sports, $73 \pm 27$ 
Table 3 Radiographic outcome (van Dijk scale)

\begin{tabular}{lllll}
\hline Patient & Case & Pre & Post & FU (months) \\
\hline 1 & 1 & 1 & 1 & 67 \\
1 & 2 & 0 & 1 & 43 \\
2 & 3 & 1 & 1 & 11 \\
3 & 4 & 0 & 0 & 8 \\
4 & 5 & 0 & 0 & 12 \\
5 & 6 & 1 & 1 & 1 \\
6 & 7 & 1 & 1 & 6 \\
7 & 8 & 1 & 1 & 17 \\
8 & 9 & 1 & 1 & 1 \\
9 & 10 & 1 & 1 & 4 \\
10 & 11 & 1 & 1 & 23 \\
11 & 12 & 0 & 0 & 2 \\
12 & 13 & 0 & 0 & 2 \\
\hline
\end{tabular}

Van Dijk scale before and after matrix-associated autologous chondrocyte implantation and autologous bone grafting (MACl/ABG). The latest radiograph before the operation "pre" and the latest available radiographs "post" were used, respectively. In case 3, the last radiograph prior to the revision operation at the medial malleolus was used as the latest follow-up radiograph to minimise bias. The time between $\mathrm{MACl} / \mathrm{ABG}$ and postoperative radiograph was defined as the follow-up (FU)

radiographs showed stage $1 \mathrm{OA}$ in one case $(33 \%)$ and no signs of OA in two cases (67\%).

Cases without previous operation regarding the affected ankle $(n=9)$ had a mean age of $18.0 \pm 2.2$ years at the time of MACI/ABG. The group consisted of three males and nine females (33\% vs 67\%), and the median BMI was $23.5 \mathrm{~kg} / \mathrm{m}^{2}$ (range $18.0-39.3 \mathrm{~kg} / \mathrm{m}^{2}$ ). In contrast, the group of cases with one or two previous operations $(n=4)$ had a mean age of $17.0 \pm 2.2$ years, a gender distribution of one male vs three females $(25 \%$ vs $75 \%$ ), and a median BMI of $23.75 \mathrm{~kg} / \mathrm{m}^{2}$ (range 22.3$\left.24.6 \mathrm{~kg} / \mathrm{m}^{2}\right)$.

Cases without previous operation showed no signs of $\mathrm{OA}$ in four cases (44\%) and stage $1 \mathrm{OA}$ according to the van Dijk classification in five cases (56\%) on pre-MACI/ ABG radiographs compared to cases with previous operation, which showed no signs of OA in one case (25\%) and stage $1 \mathrm{OA}$ in three cases (75\%) prior to MACI/ ABG.

\section{Discussion}

The aim of this study is to present clinical results after MACI/ABG for OCLTs in adolescents using PROMs. PROMs are increasingly used to evaluate the subjective outcomes of surgical interventions of the foot and ankle $[18,19]$. An analysis of the measurement properties of the FAOS and FAAM scores identified these as promising PROMs [19].

The comparability of FAOS and FAAM score values between different patients is limited as the scores represent a highly subjective patient point of view. The subjective outcomes after MACI/ABG in this study were heterogeneous. In some subscales, the values were widely scattered between the patients (e.g., FAOS subscale sports/recreational activities, FAAM subscales sports and function/sports). Overall, some patients seem to have long-term limitations, especially in sport activities (as seen in the FAOS subscale sports/recreational activities and the FAAM subscales sports and function/ sports). In addition, quality of life seems to be impaired in the long term in some patients (FAOS subscale QOL).

When interpreting the PROMs, it must be taken into account that only high-stage OCLTs (stage 4 cartilage damage according to the ICRS classification plus subchondral bony defect), which themselves represent a significant damage to the ankle, were treated with MACI/ ABG. In addition, we found a high rate of ankle OA on preoperative radiographs in these young patients (stage $1 \mathrm{OA}$ according to the van Dijk classification in eight of the 13 cases). The presence of osteophytes led to the diagnosis of stage $1 \mathrm{OA}$ in all of the cases. OA was present in cases with and without previous operations of the affected OCLT (three of four cases [75\%] vs five of nine cases [56\%]). Furthermore, OA was also detected before $\mathrm{MACI} / \mathrm{ABG}$ in both idiopathic and traumatic OCLTs (four of five [80\%] vs four of eight [50\%]). In other words, OA affected both idiopathic and traumatic cases and also cases without any previous operation of the affected ankle. This finding supports the assumption that OCLTs may lead to the development of diffuse ankle OA. However, osteochondral lesions may also be part of developing OA of the ankle due to other causes. The question is whether the clinical outcome is influenced by the initial OCLT, the surgical intervention, or the potential OA.

There is a lack of evidence about the natural history of OCLTs and the potential association between OCLT and $\mathrm{OA}$ in paediatric and adolescent patients. Edmonds et al. reported radiographic outcomes after ankle arthroscopy plus retrograde drilling in 50 ankles after a mean follow-up of $15.1 \pm 11.5$ months (range 3.2-49.1 months) [20]. The mean patient age at the time of surgery was $13.2 \pm 2.7$ years. Remarkably, the authors detected worsening signs of OA according to the KellgrenLawrence classification in $25 \%$ of cases (reported preoperative score: mean 0.42 , median 0 vs postoperative score: mean 0.60 , median 1). Patient age of 11.5 years was identified as a potential predictive value for advancing Kellgren-Lawrence stage [20]. When comparing our results to the findings of the above mentioned study, it must be considered that the lesion characteristics in both populations were different. Edmonds et al. only included OCLTs with intact overlaying cartilage, whereby the OCLTs within our study all showed significant 
cartilage damage. Nevertheless, Edmonds et al. also found signs of OA prior to surgical treatment, similar to our study.

We detected van Dijk stage progression on post- compared to preoperative radiographs in only one case. But the differences between post- and preoperative radiographs must be interpreted with caution because the time interval between MACI/ABG and the follow-up radiographs was very different between the cases.

It is unknown whether the natural history of OCLTs differ between children/adolescents and adults. In a 24year follow-up (range 7-36 years) of 13 paediatric patients with OCLT of the talar dome that were treated conservatively, Wester et al. found abnormalities in five cases in follow-up imaging, such as persistent primary lesion in three cases and loose bodies in two cases [21]. Three of these five patients had mild symptoms at follow-up. The authors concluded that OA is infrequent in paediatric OCLTs [21]. In contrast, Ikuta et al. reported a case of a 12-year-old girl with medial talar OCLT [22]. She was treated conservatively over a period of 10 years. After an interval of 4 years, she developed limitations of recreational activities and signs of OA on follow-up radiographs [22].

Weigelt et al. presented long-term clinical and radiological outcomes of 24 mainly adult OCLT patients that were treated conservatively after a mean follow-up of 14 years (range 11-20 years) [23]. The mean initial patient age was 42 years (range 10-69 years). At follow-up, 29\% of the cases showed no signs of OA, $50 \%$ stage 1 OA, and $21 \%$ stage $2 \mathrm{OA}$ according to the van Dijk classification. In this study, 15 initial radiographs were available that were compared with follow-up radiographs. At the time of follow-up, 11 cases showed no OA progression, and four cases showed progression by one grade. However, the clinical results did not correlate with the radiological findings [23].

In the present study, we did not investigate a potential correlation between the presence of pre- or postoperative $\mathrm{OA}$ and OA progression and clinical outcome, since the number of cases was too small to draw reliable conclusions. Furthermore, our cohort represents a highly selected subgroup of OCLT patients with only high-stage OCLTs.

There are several reports of good clinical outcomes following ankle arthroscopy and retrograde drilling $[4,7$, 8]. However, this technique is reserved for OCLTs with intact overlaying cartilage [24]. There is a deficit of studies on the treatment of high-stage OCLTs in children and adolescents. We assume that the preoperative OCLT stage (cartilage damage and subchondral bony defect) has a major impact on the long-term clinical and radiological outcome. Several retrospective case series reported heterogeneous clinical and radiographic results of arthroscopic BMS techniques; however, to the best of our knowledge, there is no study investigating the outcome of cartilage replacement therapies (MACI or MBMS) in combination with ABG or osteochondral transplantation in the paediatric and adolescent population.

Carlson et al. followed 22 OCLT patients with a mean age of 14.4 years (range 8-18 years) with BMS and detected high functional outcomes according to different scores after a mean follow-up of 8.3 years (range 2-27 years) [6]. Remarkably, the authors found van Dijk OA stage 0 in $56 \%$, stage 1 in 38\%, and stage 2 in $6 \%$ of the cases on postoperative radiographs. Jurina et al. reported the results of arthroscopic BMS in 13 skeletally immature patients with OCLT [5]. They detected good clinical results in 10 and fair clinical results in three cases according to the Berndt and Harty outcome question as well as significant American Orthopaedic Foot and Ankle Society (AOFAS) score improvement compared to the preoperative AOFAS score [5]. Reilingh et al. reported the outcome of operative treatment of skeletally immature OCLT patients with a mean age of 13 years who were treated with fragment fixation $(n=9)$ and debridement/BMS $(n=21)$ [3]. The BMS patients had a good outcome in 13 cases, a fair outcome in three cases, and a poor outcome in five cases, according to the Berndt and Harty outcome question. The median AOFAS score was 95 (range 45-100) at follow-up [3].

In the abovementioned study by Kramer et al. in addition to other outcome measures, the FAOS score was evaluated in 44 patients. The average FAOS score was $77 \pm 18$, which is comparable to our results (mean FAOS score $78 \pm 13$ ) [9]. However, the surgical techniques and lesion characteristics between the study by Kramer et al. and our study were different, which limits the comparability.

The outcomes of BMS techniques decline with increasing defect size and depth [25]. The threshold for cartilage replacement therapies such as MACI or MBMS is a defect size of $1.0 \mathrm{~cm}^{2}$ [10] or $1.5 \mathrm{~cm}^{2}$ [12] and greater. Giannini et al. also defined a lesion depth over 5 $\mathrm{mm}$ as an indication for bone grafting in chronic OCLTs [12]. M-BMS has the advantage of being a one-step procedure compared to MACI, which requires two operations. M-BMS showed better clinical results compared to microfracture in patellar chondral defects [26], while this was not the case for adult OCLT patients [27].

New therapeutic procedures such as differentiated to chondrocytes bone marrow mesenchymal stem cells cultured on a collagen type I/III scaffold have shown encouraging clinical results in full-thickness cartilage defects of the knee [28]. It remains to be seen whether this technique can also be successfully applied to the ankle joint.

There are recommendations for debridement without BMS for acute and small $\left(<1 \mathrm{~cm}^{2}\right)$ or partial thickness 


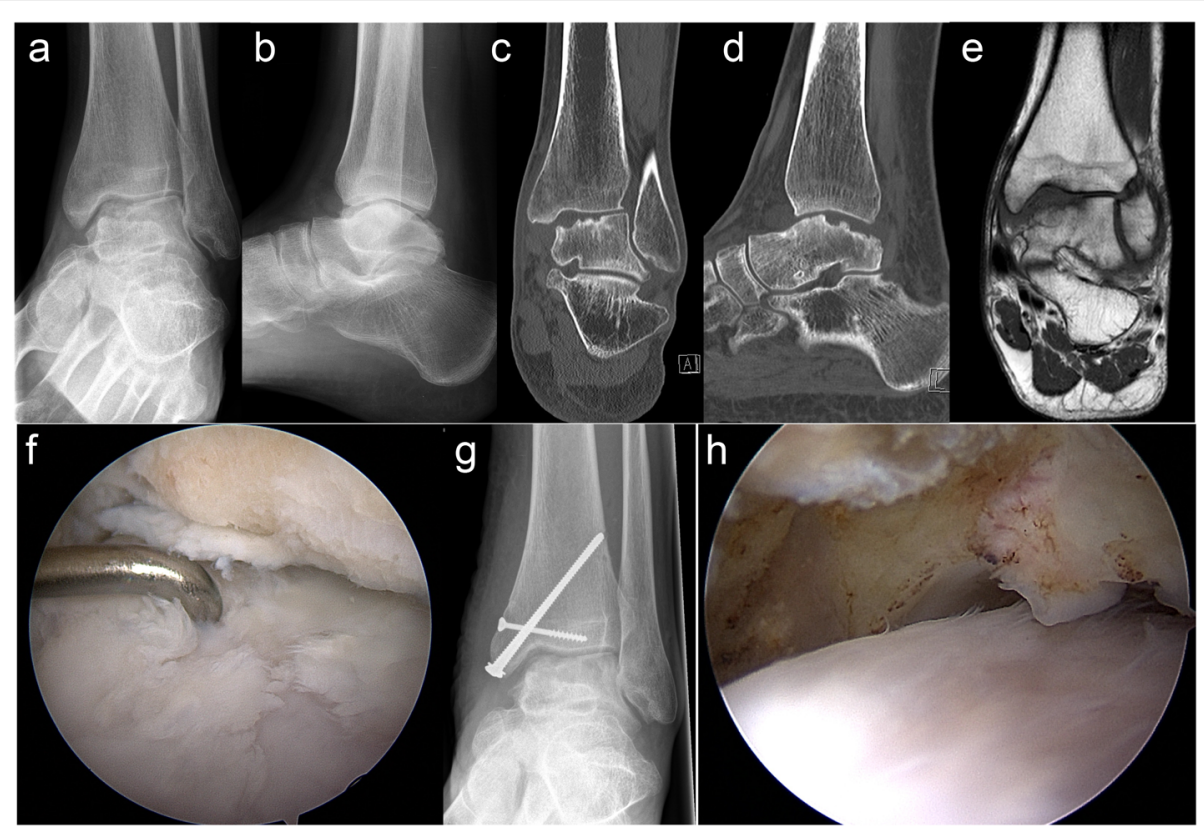

Fig. 3 Eighteen-year-old male patient (case 11) with a posttraumatic osteochondral lesion of the medial talus, which was treated with primary combined matrix-associated autologous chondrocyte implantation (MACl) via medial malleolar osteotomy with autologous bone grafting (ABG) from the ipsilateral iliac crest; preoperative antero-posterior (a) and lateral (b) radiographs; preoperative computed tomography scans in the coronary (c) and sagittal (d) plane; preoperative magnetic resonance image in the coronary plane (e); arthroscopic image at the time of chondrocyte harvesting (f) showing the cartilage damage at the medial talus and the status after debridement of a ventral tibial osteophyte; antero-posterior radiograph (g) after MACI/ABG showing screw fixation of the medial malleolar osteotomy; arthroscopic image at the time of hardware removal (h) 23 months after MACI/ABG showing the cartilage surface at the medial talus

OCLTs $[12,25]$. A recent review showed good to excellent short- and medium-term outcomes after arthroscopic debridement of focal cartilage lesions of the knee [29].

The mean patient age of the present study was higher compared to the abovementioned studies. This is partly because some cases had previous, less invasive surgical interventions at the affected OCLT prior to MACI/ABG, and MACI/ABG was used as a revision technique. Furthermore, MACI/ABG was realised in all cases in this study via a malleolar osteotomy, which should only be performed when the growth plates of the distal tibia/fibula are closed (Fig. 3).

Our results regarding OCLT location are in accord with other findings in paediatric [9] and adult OCLT patients $[27,30]$, according to which OCLTs occur more frequently at the medial than at the central or lateral talus.

This study has several limitations. First, we could not compare the results of the FAOS and FAAM scores with preoperative baseline values. This is due to the retrospective character of the study. Second, the number of cases is too small to compare different subgroups according to the clinical outcome (e.g., idiopathic vs traumatic). However, we were able to present long-term outcomes of a homogeneous study population after a standardised procedure. To the best of our knowledge, this is the first study reporting PROMs after MACI/ABG in an adolescent population.

Future studies should focus on the long-term outcomes of both operatively and non-operatively treated OCLTs. Because of the rarity of paediatric OCLTs, this should be realised via multicentre registries to generate greater study populations. Different operative techniques could be compared according to different outcome measures. Special attention should be given to the development of $\mathrm{OA}$ in the long term and the association between radiographic findings and clinical outcomes.

\section{Conclusions}

PROMs following MACI/ABG for high-stage OCLTs in adolescents are heterogeneous between patients. Longterm limitations seem to especially affect sports and recreational activities. OCLTs are associated with OA, even preoperatively. However, we did not find significant OA progression after MACI/ABG in the long term.

\section{Abbreviations}

ABG: Autologous bone grafting; ADL: Activities of daily living; BHL: BerndtHarty-Loomer; BMI: Body mass index; BMS: Bone marrow stimulation; FAAM: Foot and Ankle Ability Measure; FAOS: Foot and Ankle Outcome Score; FU: Follow-up; ICRS: International Cartilage Repair Society; MACI: Matrix-associated autologous chondrocyte implantation; MBMS: Matrix-induced bone marrow stimulation; OCLT: Osteochondral lesion 
of the talus; OA: Osteoarthritis; PROM: Patient-reported outcome measure; QOL: Quality of life; SD: Standard deviation

\section{Acknowledgements \\ Not applicable.}

\section{Authors' contributions}

DK: data analysis, writing the manuscript. CG: revision of the manuscript. SD: supervision of the project, revision of the manuscript. CK: revision of the manuscript. FS: revision of the manuscript. GK: revision of the manuscript. All authors read and approved the final manuscript.

\section{Funding}

The Deutsche Forschungsgemeinschaft and the Open Access Publishing Fund of the University of Tübingen covered $70 \%$ of the article-processing charges by the Journal of Orthopaedic Surgery and Research. Open Access funding enabled and organized by Projekt DEAL.

\section{Availability of data and materials}

The datasets generated and/or analysed during the current study are not publicly available due to German and European data protection laws.

\section{Declarations}

\section{Ethics approval and consent to participate}

The study was performed according to the ethical standards of the institutional and national research committee and with the 1964 Helsinki Declaration and its later amendments. The institutional review board approved this study (identification number: 180/2020BO1).

Patients who returned the patient-reported outcome measures gave their informed consent. For patients who were lost to follow-up, consent was waived, since in these patients only a retrospective, pseudonymised data evaluation was performed.

\section{Consent for publication}

Not applicable.

\section{Competing interests}

The authors declare that they have no competing interests.

\section{Author details}

'Department of Traumatology and Reconstructive Surgery, BG Trauma Center Tübingen, Eberhard Karls University Tübingen, Schnarrenbergstr. 95, 72076 Tübingen, Germany. ²Department of Diagnostic and Interventional Radiology, University Hospital Tübingen, Eberhard Karls University Tübingen, Hoppe-Seyler-Str. 3, 72076 Tübingen, Germany. ${ }^{3}$ Department of Radiology, BG Trauma Center Tübingen, Eberhard Karls University Tübingen,

Schnarrenbergstr. 95, 72076 Tübingen, Germany.

Received: 6 February 2021 Accepted: 24 March 2021

Published online: 08 April 2021

\section{References}

1. Kessler JI, Weiss JM, Nikizad H, Gyurdzhyan S, Jacobs JC, Bebchuk JD, et al. Osteochondritis dissecans of the ankle in children and adolescents: demographics and epidemiology. Am J Sports Med. 2014;42(9):2165-71. https://doi.org/10.1177/0363546514538406.

2. Buda R, Pagliazzi G, Castagnini F, Cavallo M, Giannini S. Treatment of osteochondritis dissecans of the talus in skeletally immature population: a critical analysis of the available evidence. Foot Ankle Spec. 2016;9(3):265-70. https://doi.org/10.1177/1938640016640889.

3. Reilingh ML, Kerkhoffs GMMJ, Telkamp CJA, Struijs PAA, van Dijk CN Treatment of osteochondral defects of the talus in children. Knee Surg Sports Traumatol Arthrosc. 2014;22(9):2243-9. https://doi.org/10.1007/s001 67-013-2685-7.

4. Masquijo JJ, Ferreyra A, Baroni E. Arthroscopic retrograde drilling in juvenile osteochondritis dissecans of the talus. J Pediatr Orthop. 2016 Sep;36(6):58993. https://doi.org/10.1097/BPO.0000000000000498.

5. Jurina A, Dimnjaković D, Mustapić M, Smoljanović T, Bojanić I. Clinical and MRI outcomes after surgical treatment of osteochondral lesions of the talus in skeletally immature children. J Pediatr Orthop. 2018;38(2):122-7. https:// doi.org/10.1097/BPO.0000000000000745.

6. Carlson MJ, Antkowiak TT, Larsen NJ, Applegate GR, Ferkel RD. Arthroscopic treatment of osteochondral lesions of the talus in a pediatric population: a minimum 2-year follow-up. Am J Sports Med. 2020;48(8): 1989-98. https://doi.org/10.1177/0363546520924800.

7. Minokawa S, Yoshimura I, Kanazawa K, Hagio T, Nagatomo M, Sugino Y, et al. Retrograde drilling for osteochondral lesions of the talus in skeletally immature children. Foot Ankle Int. 2020;41(7):827-33. https://doi.org/10.11 77/1071100720920847.

8. Ikuta Y, Nakasa T, Ota Y, Kanemitsu M, Sumii J, Nekomoto A, et al. Retrograde drilling for osteochondral lesion of the talus in juvenile patients. Foot Ankle Orthop. 2020;5(2):247301142091613. https://doi.org/10.1177/2473 011420916139.

9. Kramer DE, Glotzbecker MP, Shore BJ, Zurakowski D, Yen YM, Kocher MS, et al. Results of surgical management of osteochondritis dissecans of the ankle in the pediatric and adolescent population. J Pediatr Orthop. 2015; 35(7):725-33. https://doi.org/10.1097/BPO.0000000000000352.

10. Rothrauff BB, Murawski CD, Angthong C, Becher C, Nehrer S, Niemeyer P, et al. Scaffold-based therapies: proceedings of the International Consensus Meeting on Cartilage Repair of the Ankle. Foot Ankle Int. 2018:39(1_suppl):41S-7S.

11. Aurich M, Albrecht D, Angele P, Becher C, Fickert S, Fritz J, et al. Treatment of osteochondral lesions in the ankle: a guideline from the group "Clinical Tissue Regeneration" of the German Society of Orthopaedics and Traumatology (DGOU). Z Orthop Unfall. 2017;155:92-9.

12. Giannini S, Buda R, Faldini C, Vannini F, Bevoni R, Grandi G, et al. Surgical treatment of osteochondral lesions of the talus in young active patients. J Bone Joint Surg Am. 2005;87(Suppl 2):28-41.

13. Loomer R, Fisher C, Lloyd-Smith R, Sisler J, Cooney T. Osteochondral lesions of the talus. Am J Sports Med. 1993;21(1):13-9. https://doi.org/10.1177/0363 54659302100103.

14. van Bergen CJA, Sierevelt IN, Hoogervorst P, Waizy H, van Dijk CN, Becher C Translation and validation of the German version of the foot and ankle outcome score. Arch Orthop Trauma Surg. 2014;134(7):897-901. https://doi. org/10.1007/s00402-014-1994-8.

15. Nauck T, Lohrer H. Translation, cross-cultural adaption and validation of the German version of the Foot and Ankle Ability Measure for patients with chronic ankle instability. Br J Sports Med. 2011:45(10):785-90. https://doi. org/10.1136/bjsm.2009.067637

16. van Dijk CN, Tol JL, Verheyen CC. A prospective study of prognostic factors concerning the outcome of arthroscopic surgery for anterior ankle impingement. Am J Sports Med. 1997;25(6):737-45. https://doi.org/10.1177/ 036354659702500603

17. van Bergen CJ, Gerards RM, Opdam KT, Terra MP, Kerkhoffs GM. Diagnosing, planning and evaluating osteochondral ankle defects with imaging modalities. World J Orthop. 2015;6(11):944-53. https://doi.org/10.5312/wjo. v6.i11.944.

18. Zwiers R, Weel H, Mallee WH, Kerkhoffs GMMJ, van Dijk CN. Large variation in use of patient-reported outcome measures: a survey of 188 foot and ankle surgeons. Foot Ankle Surg. 2018;24(3):246-51. https://doi.org/10.1016/ j.fas.2017.02.013.

19. Sierevelt IN, Zwiers R, Schats W, Haverkamp D, Terwee CB, Nolte PA, et al. Measurement properties of the most commonly used Foot- and AnkleSpecific Questionnaires: the FFI, FAOS and FAAM. A systematic review. Knee Surg Sports Traumatol Arthrosc. 2018;26(7):2059-73. https://doi.org/10.1007/ s00167-017-4748-7.

20. Edmonds EW, Phillips L, Roocroft JH, Bastrom TP, Pennock AT, Chambers HG. Stable childhood osteochondral lesions of the talus: short-term radiographic outcomes suggest risk for early osteoarthritis. J Pediatr Orthop Part B. 2020;29(4):363-9. https://doi.org/10.1097/BPB.0000000000000708.

21. Wester JU, Jensen IE, Rasmussen F, Lindequist S, Schantz K. Osteochondral lesions of the talar dome in children. A 24 (7-36) year follow-up of 13 cases. Acta Orthop Scand. 1994;65(1):110-2. https://doi.org/10.3109/174536794 08993733

22. Ikuta Y, Nakasa T, Sumii J, Nekomoto A, Adachi N. Long-term natural course of the osteochondral lesion of the talus in a child: a case report. J Foot Ankle Surg. 2020;\$1067-2516(20)30347-1.

23. Weigelt L, Laux CJ, Urbanschitz L, Espinosa N, Klammer G, Götschi T, et al. Long-term prognosis after successful nonoperative treatment of osteochondral lesions of the talus: an observational 14-year follow-up study. Orthop J Sport Med. 2020;8:1-7. 
24. Shimozono Y, Brown AJ, Batista JP, Murawski CD, Gomaa M, Kong SW, et al. Subchondral pathology: Proceedings of the International Consensus Meeting on Cartilage Repair of the Ankle. Foot Ankle Int. 2018;39(1_suppl): 48S-53S.

25. Hannon CP, Bayer S, Murawski CD, Canata GL, Clanton TO, Haverkamp D, et al. Debridement, curettage, and bone marrow stimulation: Proceedings of the International Consensus Meeting on Cartilage Repair of the Ankle. Foot Ankle Int. 2018;39(1_suppl):16S-22S.

26. Migliorini F, Eschweiler J, Maffulli N, Driessen A, Rath B, Tingart M, et al. Management of patellar chondral defects with autologous matrix induced chondrogenesis (AMIC) compared to microfractures: a four years follow-up clinical trial. Life (Basel). 2021;11:141.

27. Becher C, Malahias MA, Ali MM, Maffulli N, Thermann H. Arthroscopic microfracture vs. arthroscopic autologous matrix-induced chondrogenesis for the treatment of articular cartilage defects of the talus. Knee Surg Sports Traumatol Arthrosc. 2019;27(9):2731-6. https://doi.org/10.1007/s00167-0185278-7.

28. Mardones R, Giai Via A, Pipino G, Jofre CM, Muñoz S, Narvaez E, et al. BMMSCs differentiated to chondrocytes for treatment of full-thickness cartilage defect of the knee. J Orthop Surg Res. 2020;15(1):455. https://doi.org/10.11 86/s13018-020-01852-x.

29. Totlis T, Marín Fermín T, Kalifis G, Terzidis I, Maffulli N, Papakostas E. Arthroscopic debridement for focal articular cartilage lesions of the knee: a systematic review. Surgeon. 2021; S1479-666X(20)30184-0.

30. Savage-Elliott I, Ross KA, Smyth NA, Murawski CD, Kennedy JG. Osteochondral lesions of the talus: a current concepts review and evidencebased treatment paradigm. Foot Ankle Spec. 2014;7(5):414-22. https://doi. org/10.1177/1938640014543362.

\section{Publisher's Note}

Springer Nature remains neutral with regard to jurisdictional claims in published maps and institutional affiliations.

Ready to submit your research? Choose BMC and benefit from:

- fast, convenient online submission

- thorough peer review by experienced researchers in your field

- rapid publication on acceptance

- support for research data, including large and complex data types

- gold Open Access which fosters wider collaboration and increased citations

- maximum visibility for your research: over $100 \mathrm{M}$ website views per year

At $\mathrm{BMC}$, research is always in progress.

Learn more biomedcentral.com/submissions 